\title{
TRANSPORT ORGANIZERS’ INTEGRATING ROLE IN CITY LOGISTICS
}

\author{
JAGIENKA RZEŚNY CIEPLIŃSKA \\ Faculty of Economics, WSB University in Gdansk, Poland
}

\begin{abstract}
The number of urban residents is growing by nearly 60 million people every year. With the growth of cities and urban population, cities are becoming more and more the centre of worldwide development. Being the centre of growth, cities have the additional responsibility to make development activities more sustainable and environmental friendly. Increasing urbanization requires new and innovative ways to manage the complexity of urban living and to target problems of energy consumption, resource management and environmental protection.

The present study is mostly based on investigating managers of transport and forwarding companies, public transport administrators and city board representatives within the Pomeranian region. Moreover, research is carried out on the analysis of practical solutions in the field of smart mobility solutions in European urban areas, documents of the European Commission and the publications prepared by industry associations. The theoretical part of the article is based on existing materials from public resources and author's research experience.

The study result is an authorial framework of goods' and people's transport organizer within metropolitan areas with conceptual modelling of their functions. Thus, the organizer's specialization does not depend on the subject of transportation, and their range comprehensively covers goods flows as well as passengers' transportation.

Analysis of solutions within goods and people flows within the metropolitan areas and the studies carried out on the basis of investigating key stakeholders shows that the best way within smart mobility concepts is employing specialized integrator - City Transport Organizer.

Keywords: city logistics, urban mobility, urban transport organizing
\end{abstract}

\section{INTRODUCTION}

In 2008, for the first time in history, more people lived in cities than in rural areas. It is estimated that by 2050 nearly two-thirds of the world's projected 9.7 billion people will be urban. Cities are becoming congested due to migration from rural areas, emigration from overseas as a result of globalization and the proliferation of industries and amenities. Due to the high rate of urbanization all over the world, the importance of the processes taking place within cities is increasing, thus the importance of city logistics is still growing. City logistics tends to be an important area, and it involves several levels of complexity. It consists of planning, coordination and controlling of logistic processes and various flows within urban areas. Logistic activities within cities, or especially city centres, generate external costs, therefore, looking for solutions improving the quality of life within cities is needed.

\section{SMART CITY CONCEPT IN CITY MANAGEMENT}

Facing the challenges of city management requires appropriate actions and appropriate strategies. The solution may be the application of different tools within smart city concept.

The birth of smart city idea is rooted in 'the creation and connection of

- social capital;

- information; and

- communication technology infrastructure 
in order to generate greater and more sustainable economic development and better quality of life within the urban areas' [1].

Smart cities are understood as '...cities that use information and communication technologies (ICT) to be more intelligent and efficient in the use of resources, resulting in cost and energy savings, improved service delivery and quality of life, and reduced environmental footprint-all supporting innovation and the low-carbon economy' [2].

A Smarter City systematically creates and encourages innovations in city systems that are enabled by technology; that change the relationships between the creation of economic and social value and the consumption of resources; and that contribute in a coordinated way to achieving a vision and clear objectives that are supported by a consensus among city stakeholders.

To conclude, it's likely that the following generic objectives should be considered and adapted in that process:

- 'A Smarter City is in a position to make a success of the present: for example, it is economically active in high-value industry sectors and able to provide the workforce and infrastructure that companies in those sectors need.

- A Smarter City is on course for a successful future: with an education system that provides the skills that will be needed by future industries as technology evolves.

- A Smarter City creates sustainable, equitably distributed growth: where education and employment opportunities are widely available to all citizens and communities, and with a focus on delivering social and environmental outcomes as well as economic growth.

- A Smarter City operates as efficiently \& intelligently as possible: so that resources such as energy, transportation systems and water are used optimally, providing a low-cost, lowcarbon basis for economic and social growth, and an attractive, healthy environment in which to live and work.

- A Smarter City enables citizens, communities, entrepreneurs \& businesses to do their best; because making infrastructures Smarter is an engineering challenge; but making cities Smarter is a societal challenge; and those best placed to understand how societies can change are those who can innovate within them.

- A Smarter City harnesses technology effectively and makes it accessible; because technology continues to define the new infrastructures that are required to achieve efficiencies in operation; and to enable economic and social growth' [3].

Smart city concept includes six dimensions:

- 'smart government;

- smart economy;

- smart mobility;

- smart environment;

- smart citizens;

- smart living' [4].

Although the idea of smart city was initially implemented in many cities by pursuing a sustainable energy policy, now according to the opinions of the smart urban experts, intelligent transport is essential to improving the quality of life of urban residents. So for the needs of this article, just smart mobility area will be analysed. 
Smart mobility means ICT supported and integrated transport and logistics systems within the urban areas. Its priorities focus on

- 'sustainable, safe and interconnected transportation systems within the city regarding passengers and goods transportation;

- promotion of clean and non-motorised options of transportation of goods as well as passengers;

- real-time information systems;

- transport and logistics manager engagement responsible for the flows within the urban areas' [5].

\section{CITY LOGISTICS ESSENTIALS}

Caring for the flow of goods and passengers through integrated urban logistic strategies should be a determinant of urban management. Urban logistics is a specific area where smart solutions are often used. Benefits in this regard are felt both by residents, entrepreneurs, administrators and tourists. As a result of streamlining urban flows, improved traffic flow, increased mobility and increased quality of life in the city can be observed. Furthermore, the reduction of air pollution, the reduction of noise, the shortening of travel time, the improvement of road safety and the reduction of road infrastructure degradation are of great importance.

It is difficult to find a common definition of city logistics in expert literature [6]. Various terms are used to refer to the general concept of transportation of goods, people and waste in urban areas: 'urban goods movement', 'urban logistics', 'urban freight transport' or 'urban passengers transport'. The exact definitions of these terms differ slightly as to what is and what is not included [7].

A simple definition of urban logistics states that it is planning, implementation and monitoring of economic efficiency and effectiveness of people, cargo and relevant information flows in urban areas in order to improve the quality of citizens' life. The most precise definition says it is 'the process for total optimization of logistics and transport activities by private companies with the support of advanced information systems in urban areas considering traffic environment, traffic congestion, traffic safety and energy savings within the framework of market economy' [8].

The system of urban logistics should be understood as a deliberately organized set of elements such as stakeholders, infrastructure, regulatory standards, tariffs and relationships between them, which are involved in the process pertaining to the flows of people, cargo and relevant information in urban areas. Providers of urban logistic services are expected to be one of the most important elements of the whole system, and they should offer high-quality and reasonable prices of their delivery services in the environment of congested urban areas [9].

\section{URBAN MOBILITY IMPROVEMENT CONCEPTS}

The expansion of urban structures, the increase in the number of urban population and related flows gradually contribute to the deterioration of life quality in urban areas. Therefore, some improvement of various processes is necessary. The priorities of transport policy of the European Union are defined on the basis of similar assumptions. They are oriented towards the promotion and popularization of solutions which are aimed at the improvement in life quality in urban areas through the achievement of the following objectives [10]: 
- rational use of individual means of transport;

- improvement in handling the delivery transport in city centres;

- use of smart technologies in the means of transport, infrastructure and traffic management;

- exchange of good practice referring to practical solutions for city logistics.

Practical solutions applied in the European countries as regards the improvement in city logistics may relate to the following areas [11]:

- land-use planning;

- infrastructure;

- market-based solutions;

- new technologies.

Within the scope of land-use planning measures, different practical solutions can be distinguished. Most of them are applied in European countries. They can refer to [11]:

- restricted access to certain areas, based on different criteria for vehicles;

- time slots - solution refers to situation when certain vehicles can enter certain streets;

- exclusivity zones - it consists on limiting of the number of transporters that can perform deliveries;

- adapting on-street loading zones;

- nearby delivery areas.

A more proactive approach is to incorporate freight planning into proper management and to create infrastructure by identifying areas of conflicts between freight activities and other land uses. The initiatives that are needed for proper infrastructure are the following [12]:

- urban distribution centres - collecting shipments in a specialized warehouse at the edge of the city where they are consolidated before last mile transport;

- direct injection - solution within bringing goods directly in the city using alternative transportation means;

- dedicated parking spaces for trucks - preparing special lanes for loading and unloading trucks or letting them to use bus lanes during certain times of the day;

- e-commerce pick-up points - enabling transporters to deliver parcels to single locations without having to go from door to door.

The next group of measures is based on market solutions. They come as the most common option adapted by the local authorities to reduce externalities of road transport. They can be divided into [12]:

- urban congestion charges for certain roads or areas to incentivize car users to reduce traffic in those areas;

- subsidies, tax reductions, incentives to foster the implementation of infrastructure, equipment or technology levers.

A well-known solution, that is, to make mobility of goods in urban areas more sustainable, is based on new technologies. The role of new technologies in the optimization of urban logistics can be very diverse and can be applied in different solutions, such as [12] 
- intelligent transport system;

- Real-time information system;

- alternative transportation means;

- crowd-sourced delivery and transport solutions.

Most of the above-mentioned practical solutions are successfully applied in various European countries with the help of the European Union funds. Moreover, different solutions and measures aimed at improving flows within urban areas can come from the stakeholder engagements. Stakeholder engagement is becoming increasingly recognized as an important part of any decision-making process. Successful collaborative partnerships between particular stakeholders can lead to the formulation of high-impact freight strategies that consider logistic needs of the city, businesses, transport operators and local residents. Given the complexity of the participative approach, which includes all of the above, the involvement of different players should be stimulated and maximized from the very beginning of the planning stage.

The most common tools applied to involve stakeholders are [11]

- freight quality partnerships are to bring together the public and the private sector to discuss problems, identify and implement solutions within freight transport activities;

- freight advisory boards and forums are opportunity for stakeholders to meet and discuss challenges and chances of the freight space within the city;

- city logistics manager (CLM) function.

The function of CLM is designed to reduce demand in relation to the mobility of goods in urban areas. The main functions of CLM concerns

- 'classification and analysis of the situation characteristic of an urban context;

- discussion and sharing with the key local actors;

- definition of shared intervention strategies to apply to the surveyed urban context;

- preliminary, definitive and executive planning of the urban freight logistics mode;

- monitoring and evaluation of impacts of the planned and implemented urban freight transport modes' [11].

The mobility manager represents real intermediaries between the various local stakeholders and the public authority; their task is to reconcile the needs and demands of different companies, businesses and associations with those of the public authority and to select proposals for shared actions and plans.

\section{TRANSPORT ORGANIZERS - THEIR INTEGRATING ROLE IN CITY LOGISTICS}

City logistics concept comes from some well-established and firm logistic principles such as

- coordination of activities related to the systemic approach,

- orientation towards integrated flows and

- consideration of problems viewed from a holistic point of view.

Considering the case in which a manager responsible for city logistics is appointed for a particular administrative area, it may facilitate the achievement of the assumed aims of city logistics, which are additionally promoted in the European Union transportation policy. It 
is assumed that disintegration lowers the efficiency of transport, and it introduces irrational distribution of transport tasks; in this way, it contributes to the generation of costs which are too high or unnecessary. Integration of transport may have various forms, scopes and levels. The arguments for the necessity of integration are the integrating concepts referring to the organization of freight transport and the organization of passenger transport. Their scope incorporates some specified fields in the transport sector; however, they differ in terms of transported objects, handled by particular organizations which specialize in such services. Some concepts refer to the integration in the spatial aspect and to the integration of transport in the regional aspect. All the integrating concepts feature a superior entity, responsible for the course of transport processes, synchronization and coordination which are required during such processes.

Therefore, the objectives of city logistics are quite difficult to achieve in terms of the improvement in flows in urban areas, without their coordination provided by a specialized entity [11]. Such an entity should be a coordinator, an organizer of the integrated system of urban transport, which would not differentiate its operation in terms of transported objects, but which would comprehensively make all its implemented functions universal in the administrative area in which it operates; such an entity should refer to the concept of the manager of city logistics. By assumption, city logistics is an element of the state economic policy, and one of its permanent characteristics is the long-term intervention of the state. In the model of city logistics, the solutions that involve the public administration as the main stakeholder, which offers its own funds, are widely preferred. Considering that fact, an organizer of city logistics should be employed by the administrative authorities of particular urban areas [13].

While implementing such aims and facing challenges related to the improvement in flows in urban areas, an organizer of city logistics should strive for transport integration. The aims assumed for the operation of such an entity should be the following [14]:

- development of an integrated system of freight and passenger transport;

- finding possibilities for the implementation of the transport policy assumptions;

- rationalization of the transport system costs;

- satisfaction of freight shippers' and public transport of passengers' needs;

- providing services of higher quality than in the situation of transport disintegration; and

- improvement of the competitive position of public transport in regard to individual transport.

A wide scope of activities implemented by the organizer of the integrated transport system requires this entity to approve solutions that have been precisely developed for the particular area. The variety of management fields, in which the organizer of the integrated system of transport is supposed to operate, gives the possibility to define some universal problems for the most areas of such operation. However, during the implementation of the specific activities, it is necessary to consider the specific character of the particular transport sectors. A more precise definition referring to the operation of such an entity requires a division of its functions into the functions that are implemented during its current operation and the functions that are performed within a strategic long-time perspective.

Furthermore, while dividing the functions of the organizer into operational and strategic, it is possible to state that the longer the time perspective for a particular task is, the more possibilities appear and the higher willingness of the organizer becomes to make its approach more universal. Analogically, the more a particular activity is related to the operational function, 
the higher the necessity becomes to adopt an individualized approach. The operational functions of the organizers include:

- development and provision of information about transport functioning;

- promotion of services;

- development of schedules for regular connection lines;

- pricing services;

- distribution of services;

- supervision over the proper implementation of contracts.

The strategic functions include:

- construction of integration hubs;

- surveying the demand and requirements for transport;

- provision of proper conditions for transport functioning/standardization of services;

- planning the development of transport.

\section{CITY LOGISTICS TRANSPORT ORGANIZERS - THEIR FUNCTIONS IN CITY LOGISTICS IMPROVING}

The above-mentioned functions performed by the organizer contribute - to various extent to the achievement of the main aim, which is namely the improvement in freight and passenger flows in urban areas.

To verify his functions in terms of such contributive influence, some criteria have been assumed as regards their adequacy, efficiency and effectiveness. Considering the context of the influence exerted by the functions of the organizer on the improvement in urban flows, the adequacy criterion is related to the scope of the organizer's operation, the competences required to perform the particular functions and all the required and necessary tools to do it. The efficiency refers to the real outcomes that result from the performed function in relation to the intended aims. Thus, the measure of efficiency is determination of how close it is for the organizer to achieve the aims that have been assumed for a particular cycle of operation. The effectiveness is related to the performance of the aim functions and with the development of the most advantageous relations between the incurred expenses and the obtained results. The results of the research study and analysis allow us to characterize the function data and to determine to what extent they meet the above-mentioned criteria.

\section{SUMMARY}

As a result of the activities performed by the operator of the integrated system of transport, it is possible to achieve considerable benefits, not only for the service recipients but also for the whole structure of the transport system. The system benefits may be related to the sustainable development of transport, which takes place in accordance with the pro-ecological requirements and the economic growth of the particular area. The benefits for service recipients take the following forms: the higher level of the above-mentioned services that are offered within the frame of the integrated system of transport, an increase in the attractiveness of the transport offer, better prices and higher quality, lower transport costs, an access to a comprehensive offer provided by the organizer and an access to the detailed information on transport possibilities. 
Table 1: Function of transport organizer meeting the objectives of city logistics improvements (source: own elaboration).

\begin{tabular}{llll}
\hline Function & Adequacy & Efficiency & Effectiveness \\
\hline Information about services & $+*$ & + & -+ \\
Promotion of services & -+ & -+ & - \\
Development of schedules for regular & -+ & + & + \\
connection lines & & & -+ \\
Pricing of the services & -+ & + & -+ \\
Distribution of the services & -+ & + & -+ \\
Supervision over the operators & + & + & + \\
Construction of integration hubs & + & + & - \\
Surveying the demand and requirements for & -+ & - & -+ \\
transport & & & + \\
Standardization of services & + & + & + \\
Planning the development of transport & + & + & + \\
\hline
\end{tabular}

Source: ${ }^{*}+{ }^{\prime}$ - a function that fully meets the objectives of the improvement in city logistics; - a function that meets the objectives of the improvement in city logistics to a large extent; '-+' - a function that meets the objectives of the improvement in city logistics to a little extent; '-' a function that does not meet the objectives of the improvement in city logistics.

\section{REFERENCES}

[1] Dameri, R.P. \& Garelli, R., Measuring business benefits and performance in smart city. Proceedings of the 9th European Conference on Innovation and Entrepreneurship, 2014.

[2] Cohen, B. \& Munoz, P., The Emergence of the Urban Entrepreneur. How the Growth of Cities and the Sharing Economy Are Driving a New Breed of Innovators, Praeger: California, 2016.

[3] The Urban Technologist, Seven steps to a Smarter City; and the imperative for taking them, 2013 available at https://theurbantechnologist.com/tag/worldbank/ (accessed 20 April 2017).

[4] Lombardi, P., Giordano, S., Farouh, H. \& Yousef, W., Modelling the smart city performance, Innovation: The European Journal of Social Science Research, 25(2), 2009. http://dx.doi.org/10.1080/13511610.2012.660325

[5] Tokoro, N., The Smart City and the Co-creation of Value: A Source of New Competitiveness in a Low-Carbon Society, Springer: Japan, 2016.

[6] Szołtysek, J., City Logistics Concepts. University of Economics Publishing House: Katowice, 2007.

[7] Law, N. (eds.), Transforming Urban Transport. The Ethics, Politics and Practices of Sustainable Mobility, Routledge: New York, 2013.

[8] Taniguchi, E., Concepts of city logistics for sustainable and liveable cities. Procedia - Social and Behavioral Sciences, 151, available at http://www.sciencedirect.com/ science/article/pii/S1877042814054718, 2014 (accessed 20 March 2017).

[9] Ehmke, J., Integration of Information and Optimization Models for Routing in Urban Logistics, Springer, available at http://www.springer.com/gp/book/9781461436270, 2012 (accessed 20 January 2017). 
[10] Inner Urban Freight Transport and City Logistics, EU-funded Urban Research. Transparences 2013, available at www.eu-portal.net, 2013 (accessed 20 January 2017).

[11] Civitas Wiki, Smart Choices for Cities. Making Urban Freight Logistics More Sustainable, available at http://www.eltis.org/sites/eltis/files/trainingmaterials/civ_pol-an5_ urban_web-1.pdf, 2015 (accessed 20 January 2017).

[12] Van Audenhove F.J., de Jongh S., Durance M Urban Logistic, How to Unlock Value from Last Mile Delivery for Cities, Transporters and Retailers, Arthur D. Little FUM, 2015.

[13] Witkowski, K., Urban Logistics Aspects in Transport Infrastructure Management, PWSZ Publishing House: Sulechów, 2007.

[14] Kaszubowski, D., Determination of objectives for urban freight policy. LogForum, 4, p. 10, 2014. http://www.logforum.net/vol10/issue4/no5 